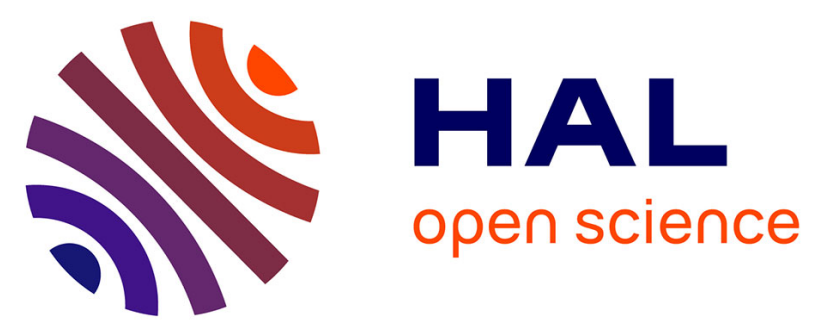

\title{
RFID Integration for Material Management Considering Engineering Changes in ETO Industry
}

Quan Yu, Pavan Kumar Sriram, Erlend Alfnes, Jan Ola Strandhagen

\section{To cite this version:}

Quan Yu, Pavan Kumar Sriram, Erlend Alfnes, Jan Ola Strandhagen. RFID Integration for Material Management Considering Engineering Changes in ETO Industry. IFIP International Conference on Advances in Production Management Systems (APMS), Sep 2016, Iguassu Falls, Brazil. pp.501-508, 10.1007/978-3-319-51133-7_60. hal-01615740

\author{
HAL Id: hal-01615740 \\ https://hal.inria.fr/hal-01615740
}

Submitted on 12 Oct 2017

HAL is a multi-disciplinary open access archive for the deposit and dissemination of scientific research documents, whether they are published or not. The documents may come from teaching and research institutions in France or abroad, or from public or private research centers.
L'archive ouverte pluridisciplinaire HAL, est destinée au dépôt et à la diffusion de documents scientifiques de niveau recherche, publiés ou non, émanant des établissements d'enseignement et de recherche français ou étrangers, des laboratoires publics ou privés. 


\title{
RFID Integration for Material Management Considering Engineering Changes in ETO Industry
}

\author{
Quan Yu, Pavan Kumar Sriram, Erlend Alfnes and Jan Ola Strandhagen \\ Norwegian University of Science and Technology, Trondheim, Norway \\ \{Quan.yu, pavan.sriram, erlend.alfnes, ola.strandhagen\}@ntnu.no
}

\begin{abstract}
Radio Frequency Identification (RFID) is a type of auto-identification technique developed in 1950s. However, its wide applications in manufacturing industries does not start until early 2000s. Discussions about applications of RFID in Engineer to Order (ETO) industry have been raised since mid-2000s. Over a decade's technical development, it is becoming a common view that RFID is an important part of Cyber Physical Systems, Internet of Things, or Industry 4.0. Although researchers have started discussion about RFID applications in ETO industry, it is not well addressed that how RFID can be applied for the material management with respect to engineering changes (ECs), which has strong impacts on an ETO company. This paper reviews RFID applications in ETO industry and gives suggestions on how an RFID system can be integrated in an ETO company? How has RFID been utilized for material management under engineering changes? And what is the general framework of RFID in material management in ETO industry?
\end{abstract}

Keywords: RFID $\cdot$ ETO $\cdot$ Engineering changes $\cdot$ Material management

\section{Introduction}

Radio Frequency Identification (RFID) is one of auto-identification techniques developed in 1950s, which has increasing applications in manufacturing industries as a decisive data collection approach since 2000s [1]. Discussions about applications of RFID in Engineer to Order (ETO) industry have been raised since later-2000s [2], and still continue [3] partially because the benefits of applying RFID in ETO industry are obscured regarding higher initial investment than general barcode systems. Discussions on benefits of RFID application in supply chain started from mid 2000s [4-6]. As barcode technology is a well-accepted identification approach in manufacturing companies for quite a long time, it is not a one-step process to use RFID as a substitution. Concurrent operation for RFID and barcode has been systematically studied [7].

Furthermore, an RFID system is a front-end system for data accessing rather than an alternative of an ICT system for resource management. Thereby, RFID is often discussed with ICT system together [1, 8, 9]. It will not be economical and even feasible solution to use RFID without the integration with an ICT system. Additionally, it is quite often for an ETO company to have engineering changes due to high probability of design and production changes; while efficient material management can provide an

adfa, p. 1, 2011.

(C) Springer-Verlag Berlin Heidelberg 2011 
opportunity to increase competitiveness because materials account for 50-60 percent of total project costs [10]. This paper reviews applications of RFID in ETO industry, mainly focusing on material management and gives suggestions of utilizing RFID for material management under engineering changes, which provides a reference for ETO industry to implement RFID technique.

\subsection{RFID technique and characteristics}

RFID uses a wireless non-contact radio system to transfer data from a tag attached to an object, for the purposes of identification and tracking. In such a system, RFID tags are attached to physical objects, which are wirelessly interrogated by antennas powered by RFID readers. Tags respond with some identifying information that may be associated with arbitrary data records, which makes an RFID system as a type of auto-identification system. Multiple readers and antennas are commonly used to build an RFID system as shown in Fig. 1.

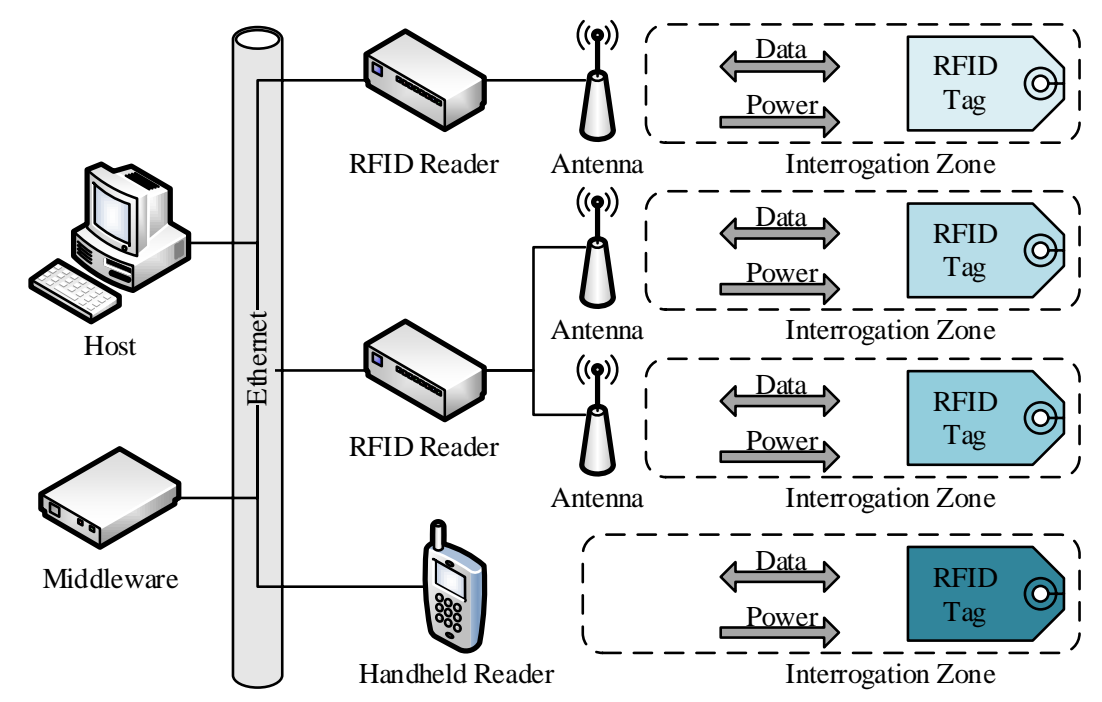

Fig. 1. A general RFID system

Main characteristics of RFID include non-line-of-sight data access and rewriteable on-chip data, which enable functionalities of remote and batch accessing, real-time accessing on-chip memory such as data retrieving, appending, erasing and protecting. In an RFID system, it is the RFID tag that is utilized as the data carrier, while other devices are used for accessing, transferring and managing the on-chip data. The working distance and the cost of an RFID tag depends on the working frequency and the additional power supply with the RFID tag. Characteristics can be compared as shown in Table 1. 
Table 1. Characteristics of passive RFID systems working at different frequencies

\begin{tabular}{llll}
\hline \multirow{2}{*}{ Characteristics } & \multicolumn{3}{c}{ Working frequency } \\
\cline { 2 - 4 } & Low & High & Ultra-high \\
\hline Frequency & $30-300 \mathrm{KHz}$ & $3-30 \mathrm{MHz}$ & $300-3000 \mathrm{MHz}$ \\
Reading distance & $0.1 \mathrm{~m}$ & $1 \mathrm{~m}$ & $12 \mathrm{~m}$ \\
Applications & Access control & eTicket & Inventory manage- \\
& Livestock tracking & Payment & ment \\
& & & Many others \\
Standards & ISO14223 & ISO 15693 & EPCglobal Gen2 \\
& ISO/IEC 18000-2 & ISO/IEC 18902 & (ISO 18000-6c) \\
& & etc. & \\
Cost & High & Medium & Low \\
Sensitivity & Low & Medium & High \\
\hline
\end{tabular}

Potential applications at different decision levels based on these two characteristics are shown in Table 2.

Table 2. Applicability of RFID

\begin{tabular}{ll}
\hline Decision level & Applicability \\
\hline Strategic level & Information sharing \\
& Increasing visibility \\
Tactical level & Tracing and tracking \\
& Decentralized data storage \\
& Life-cycle management \\
& Lead time reduction \\
Operational level & Far/near field identification \\
& Real-time locating system (RTLS) \\
& Processing history recording \\
& Automated item registration \\
& BOM recording \\
& Maintenance history recording \\
\hline
\end{tabular}

\subsection{Material management under engineering changes in ETO}

ETO is a strategy for manufacturing one-of-a-kind products (OKP) [11]. ETO companies are faced with the increasing complexity of products, production structures and processes [12]. ETO environment is characterized mostly by large and complex products which are designed and produced by customers' requirements. Products in this type of supply chain are required in low quantities and sometimes in medium volumes, but generally they contain a diversity of components in a complex combination. Each component should be assigned to specific operation in the production.

Engineering changes are considered as a major obstacle to the delivery of the product in ETO environment. Four main factors effecting engineering change are identified, 
including unidentified change propagation, knowledge management, distributed environment and capacity and congestion [10].

Material planning which also named as material management concerns balancing supply and demand by initiating, controlling and monitoring of production and purchasing orders to allow the efficient material flow going without interruptions throughout the production. Overall task of material planning process is to ensure material availability at the right stage of production and at the right time. To do so material planning uses bill of materials, inventory data, and data from master production schedule in order to determine time-phased plans for all components and raw materials required for production. Material planning process includes broad set of tasks and activities like planning required materials, sup-plier selection, purchasing, inventory management and forecasting. Therefore, this process is not only simple computer calculations but also it includes an effective communication mechanisms, education activities and training programs. The material planning process starts when the order is received, materials specifications and materials coding systems are established and bill of materials is created. In order to link bill of materials with process structure, each component in the bill of materials should be assigned to specific operations in the production.

Having a supply chain with large number of suppliers creates even greater need for an effective and efficient management of material flow, as it is required to take into account deliveries of numerous components from different suppliers [13]. The material management starts when the order is received, materials specifications and materials coding systems are established and bill of materials is created. Material management uses bill of materials, inventory data, and data from master production schedule in order to determine time-phased plans for all components and raw materials required for production, including broad set of tasks and activities like planning required materials, supplier selection, purchasing, inventory management and forecasting.

\section{Applications of RFID in ETO industry}

The earliest application of RFID in ETO industry was component tracking, similar as in other industries. RFID was tested in construction industry for tracking components from a precast storage yard to a construction site [14] and providing a reference for maintenance service [2]. In addition, researchers used RFID for managing life-cycle data of ETO construction components [15]. Based on component tracking, main RFID applications occurred in ETO fields including item management [16], lead time estimation [17], and operation times estimation [18]. Shop floor monitoring was another commonly used in for manufacturing industries [19-21].

As mentioned above, processes integration has considerable potential to improve performance of an ETO company [9, 22]. An ICT system is vital to implement RFID in material management. Regarding this point, ubiquitous work systems [23] and current ERP system adaption [24] are studied by researchers to improve ETO production from the ICT perspective. 
RFID is a decisive technique to enhance the performance of an MES/ERP. Regarding the integration of RFID with an MES/ERP, applications can generally cover identifying objects, realization of online interfaces, intra-enterprise logistics, quality management, access and attendance control and shop floor control [1, 9, 25]. ERP system has developed interface for RFID data transmission [8].

Ship building is another section where RFID is used for material management [16], ship block positioning during the assembly [26, 27] and safety management [28]. Besides implementation studies, researchers also focused on factor analysis in adoption process of vertical supply chains[29]. RFID also contributes in information sharing between different actors i.e. clients and suppliers within the supply chain [3].

\section{$3 \quad$ RFID integration framework}

To successfully implement RFID in an ETO environment, it is the first and foremost thing that integrating the RFID with the management system. Although standards are being established and interfaces are provided by commercial software, e.g. the AutoID infrastructure of SAP and BizTalk server for Microsoft Dynamics AX, they are relatively focused on business processes. Regarding complex requirements under high engineering changes probability, it is more important to embed the engineering related information in the RFID tag from the management system, other than the identification of the tracked item. However, this step is always performed by the RFID system provider without knowing well about the ETO process, which produces a large gap between a local test and the global feasibility. Performance indicators for Materials Management were proposed under engineering change [13] as shown in Fig. 2, providing a reference for the intervention of an RFID system.

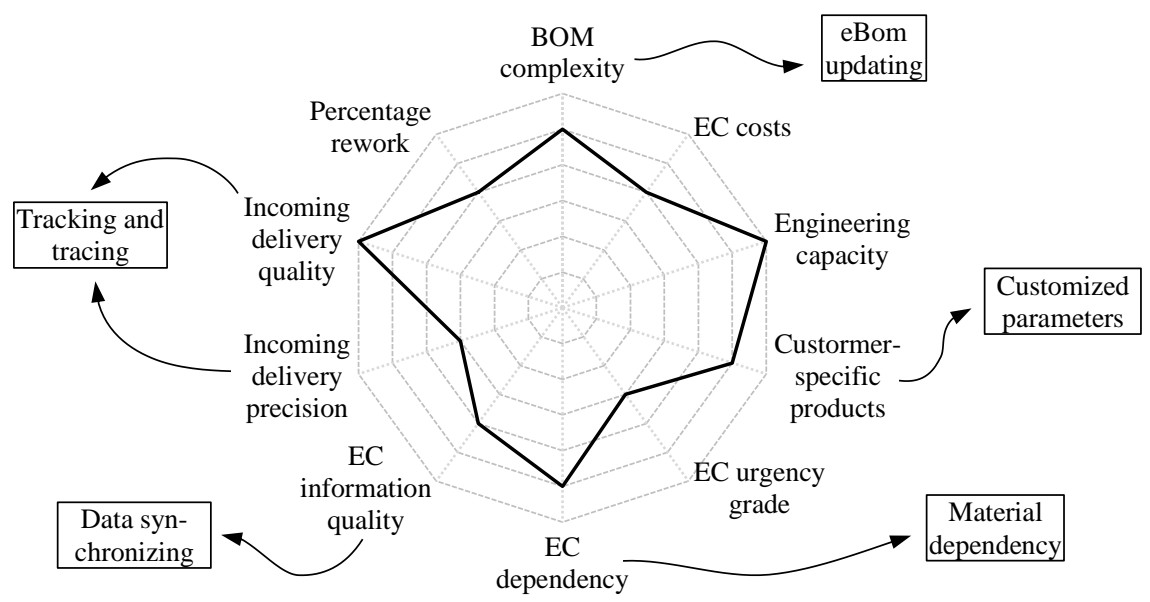

Fig. 2. Performance indicators for Materials Management under ECs (based on [13]) and relevant RFID modules 
According to performance indicators in Fig. 2, five RFID modules are expected especially for material management considering ECs as described in Table 3.

Table 3. RFID modules for material managment

\begin{tabular}{ll}
\hline Module & Description \\
\hline eBOM updating & $\begin{array}{l}\text { Designed for eBOM tag, which keeps detailed BOM and } \\
\text { revision history }\end{array}$ \\
$\begin{array}{l}\text { Customized parame- } \\
\text { Aim at special orders, which stores order specified engi- } \\
\text { neering parameters, suppliers, customers, etc. } \\
\text { Material dependency } \\
\text { To record dependencies between orders/materials, for a } \\
\text { quick lookup if ECs happen } \\
\text { To setup an error-free data updating mechanism, and en- } \\
\text { sure all confirmed changes are synchronized both in tag } \\
\text { and database } \\
\text { Tracking and tracing } \\
\text { (delivery reporting) }\end{array}$ & $\begin{array}{l}\text { Especially for real-time delivery reporting, giving a clear } \\
\text { picture of current state to decision makers }\end{array}$ \\
\hline
\end{tabular}

Among five modules above, data synchronizing needs more attention because it ensures the timely and accurate information before any decision is made. As distributed environment is one of the most important factors effecting EC [10], local ECs must be reported and updated in time for all relevant processes, so that misoperations can be avoided.

Hereby, RFID integration principles are proposed as a reference for designing an RFID system regarding engineering changes in ETO environment.

1. Evaluate components with high engineering changes probability.

2. Select suitable RFID devices according to characteristics of monitored components.

3. Main parameters related to engineering changes, suppliers and clients must be defined and pre-allocated in RFID tags referring performance indicators for Materials Management.

4. RFID data must be accessible both online and offline. Synchronization mechanism should be designed considering the network availability.

5. Authorize shared information in accordance with role of partners, i.e. suppliers and clients. On-chip data should be segmented so that they are visible to relevant partners.

\section{Conclusions}

RFID is becoming a promising technology and draws increasing attention with the improvement of technical performance and reliability. However, regarding complex engineering changes in ETO industry, material management always needs a tailor-made technical solution, so that RFID technique needs to be adapted and integrated to the ICT system to achieve the efficient management and maximum benefits. Current researches are still mainly focusing on components tracking and locating at the shop floor 
level. To be noticed, it is a trend to involve information sharing via RFID system. However, it cannot be ignored that the engineering changes connect component monitoring and information sharing process, and related information must be reflected in the RFID tag via management system to improve the production performance.

\section{References}

1. Günther, O.P., Kletti, W., Kubach, U.: The Role of Manufacturing Execution Systems. RFID in Manufacturing, pp. 35-59. Springer Berlin Heidelberg (2008)

2. Ergen, E., Akinci, B., Sacks, R.: Life-cycle Data Management of Engineered-to-Order Components Using Radio Frequency Identification. Adv. Engin. Infor. 21, 356-366 (2007)

3. Pero, M., Rossi, T.: RFID Technology for Increasing Visibility in ETO Supply Chains: A Case Study. Production Planning \& Control 25, 892-901 (2014)

4. Uckelmann, D., Hamann, T., Mansfeld, J.: Strategic Benefit Potentials of RFID Application in Supply Chains. In: 5th European Workshop on RFID Systems and Technologies, 1-9 (2009)

5. Vance, A.: An Empirical Investigation of the Potential of RFID Technology to Enhance Supply Chain Agility. In: Baskerville, R., Mathiassen, L., Pries-Heje, J., DeGross, J. (eds.) Business Agility and Information Technology Diffusion, 180, 147-156. Springer US (2005)

6. Chen, J.C., Cheng, C.-H., Huang, P.B.: Supply Chain Management with Lean Production and RFID Application. Expert Systems with Applications 40, 3389-3397 (2013)

7. Schmidt, M., Thoroe, L., Schumann, M.: RFID and Barcode in Manufacturing Logistics: Interface Concept for Concurrent Operation. Inf. Syst. Manage. 30, 100-115 (2013)

8. Knolmayer, G.F., Mertens, P., Zeier, A., Dickersbach, J.T.: SAP Systems for Supply Chain Management. Supply Chain Management Based on SAP Systems, 73-159. Springer Berlin Heidelberg (2009)

9. Canetta, L., Salvadè, A., Schnegg, P.A., Müller, E., Lanini, M.: RFID-ERP Key Data Integration Challenges. In: Canetta, L., Redaelli, C., Flores, M. (eds.) Digital Factory for Human-oriented Production Systems, pp. 73-95. Springer London (2011)

10. Sriram, P.K., Dreyer, H.C., Alfnes, E.: Understanding Key Engineering Changes for Materials Management in ETO Environment. In: Umeda, S., Nakano, M., Mizuyama, H., Hibino, H., Kiritsis, D., von Cieminski, G. (eds.) Advances in Production Management Systems: Innovative Production Management Towards Sustainable Growth: IFIP WG 5.7 International Conference, APMS 2015, Tokyo, Japan, September 7-9, 2015, Proceedings, Part II, pp. 256-262. Springer International Publishing, Cham (2015)

11. Adrodegari, F., Bacchetti, A., Pinto, R., Pirola, F., Zanardini, M.: Engineer-to-Order (ETO) Production Planning and Control: An Empirical Framework for Machinery-Building Companies. Production Planning \& Control 26, 910-932 (2015)

12. Váncza, J., Monostori, L., Lutters, D., Kumara, S.R., Tseng, M., Valckenaers, P., Van Brussel, H.: Cooperative and Responsive Manufacturing Enterprises. CIRP Annals - Manufacturing Technology 60, 797-820 (2011)

13. Sriram, P.K., Andersen, B., Alfnes, E.: Designing a Performance Measurement System for Materials Management Under Engineering Change Situations in ETO Environment. In: Umeda, S., Nakano, M., Mizuyama, H., Hibino, H., Kiritsis, D., von Cieminski, G. (eds.) Advances in Production Management Systems: Innovative Production Management Towards Sustainable Growth: IFIP WG 5.7 International Conference, APMS 2015, Tokyo, Japan, September 7-9, 2015, Proceedings, Part II, pp. 263-270. Springer International Publishing, Cham (2015) 
14. Ergen, E., Akinci, B., Sacks, R.: Tracking and Locating Components in a Precast Storage Yard Utilizing Radio Frequency Identification Technology and GPS. Automation in Construction 16, 354-367 (2007)

15. Yin, S.Y.L., Tserng, H.P., Wang, J.C., Tsai, S.C.: Developing a Precast Production Management System Using RFID Technology. Automation in Construction 18, 677-691 (2009)

16. Desselles, L., Sarder, M.D.: RFID Enabled Material Management at US Ship Building Industry. In: IIE Annual Conference and Expo 2010. Institute of Industrial Engineers, (Year)

17. Zhong, R., Huang, G., Dai, Q.-y., Zhang, T.: Estimation of Lead Time in the RFID-Enabled Real-Time Shopfloor Production with a Data Mining Model. In: Qi, E., Shen, J., Dou, R. (eds.) The 19th International Conference on Industrial Engineering and Engineering Management, pp. 321-331. Springer Berlin Heidelberg (2013)

18. Zhong, R., Huang, G., Dai, Q.Y., Zhang, T.: Mining SOTs and Dispatching Rules from RFID-Enabled Real-Time Shopfloor Production Data. Journal of Intelligent Manufacturing 25, 825-843 (2014)

19. Leung, Y.K., Choy, K.L., Kwong, C.K.: Development of a Real-Time Collaborative Process Planning Management System for the Mould Industry. In: Management of Engineering \& Technology, 2008. PICMET 2008. Portland International Conference on, pp. 266-275. (Year)

20. Leung, Y.K., Choy, K.L., Kwong, C.K.: A Real-Time Hybrid Information-Sharing and Decision Support System for the Mould Industry. The Journal of High Technology Management Research 21, 64-77 (2010)

21. Poon, T.C., Choy, K.L., Lau, H.C.W.: An Efficient Production Material Demand Order Management System for a Mould Manufacturing Company. Production Planning \& Control 22, 754-766 (2011)

22. Hicks, C., McGovern, T., Earl, C.F.: Supply Chain Management: A Strategic Issue in Engineer to Order Manufacturing. International Journal of Production Economics 65, 179-190 (2000)

23. Husejnagić, D., Sluga, A.: A Conceptual Framework for a Ubiquitous Autonomous Work System in the Engineer-To-Order Environment. The International Journal of Advanced Manufacturing Technology 78, 1971-1988 (2015)

24. Nakayama, R.S., de Mesquita Spinola, M.: Production Planning and Control in Small Engineer-to-Order Companies: Understanding Difficulties and Pragmatic Approach. In: Management of Engineering and Technology (PICMET), 2015 Portland International Conference on, pp. 1449-1460. (Year)

25. Wang, M.L., Qu, T., Zhong, R.Y., Dai, Q.Y., Zhang, X.W., He, J.B.: A Radio Frequency Identification-Enabled Real-Time Manufacturing Execution System for One-of-a-Kind Production Manufacturing: A Case Study in Mould Industry. International Journal of Computer Integrated Manufacturing 25, 20-34 (2012)

26. Lee, S., Eun, S., Jung, J.J., Song, H.: Application of Sensor Technology for the Efficient Positioningand Assembling of Ship Blocks. Int. J. Nav. Archit. Ocean Eng. 2, 171-176 (2010)

27. Jeong, S.H., Son, H.W.: UHF RFID Tag Antenna for Embedded Use in a Concrete Floor. IEEE Antennas Wirel. Propag. Lett. 10, 1158-1161 (2011)

28. Yun, J.M., Park, P.: Development of Industrial Safety Management System for Shipbuilding Industry Using RFID/USN. In: 9th IEEE International Conference on Ubiquitous Intelligence and Computing, 285-291 (2012)

29. Quetti, C., Pigni, F., Clerici, A.: Factors Affecting RFId Adoption in a Vertical Supply Chain: The Case of the Silk Industry in Italy. Production Planning \& Control 23, 315-331 (2012) 